\title{
Technical and Economic Analysis of Scrubbers
}

\author{
Thrasivoulos Bakatselos \\ Dept. of Industrial Design and \\ Production Engineering \\ University of West Attica \\ Athens, Greece
}

\author{
Nikitas Nikitakos \\ Dept. Shipping, Trade and \\ Transport \\ Universtiy of Aegean \\ Greece
}

\author{
Dimitrios Papachristos \\ Dept. of Industrial Design and \\ Production Engineering \\ University of West Attica, Athens, \\ Greece
}

\begin{abstract}
The newly-introduced environmental regulations regarding the fuels' content in sulphur inside ECA zones, creates a new reality for shipping companies. In order to face this reality, the ship-owners have to choose between consuming distillate fuels or conventional fuels along with the installation of a scrubber. This multifarious problem requires the presentation of the two available means of conformity, so the reader can fully comprehend the difficulties of the issue. In the meanwhile, the majority of the published available bibliography was reviewed, regarding the environmental and economic assessment. Moving forward, a sophisticated ultralarge containership, which trades in the busiest ports of Europe and Asia, was used for assessing the economics of scrubber installation. Four possible scenarios are examined concerning the exposure time in ECA zone and different operating profiles.
\end{abstract}

\section{Keywords}

Scrubber, ECA, Exhaust gas emission, Low sulphur fuel oil, Exhaust gas cleaning system

\section{INTRODUCTION}

This diplomatic work came from the intense concern of the author and the majority of the shipping community, about the tightest regulatory framework in force on $1 / 1 / 2015$, which points out the use of fuels with a maximum sulfur content of $0.1 \%$ within the ECA zones. The need to comply with new environmental regulations and the limited number of available alternatives on the market, make it even more pressing and urgent to choose the way to comply with the lowest possible cost and maximum performance.

The alternative modes of compliance that were readily available during this work were two: either the use of lowsulfur fuels (basically MGO / MDO) within the ECA zone or the consumption of conventional HFOs along with the installation of systems washing off exhaust gases (scrubbers). Since this work was done after the implementation of the new regulations, it was considered appropriate for the author to compare and evaluate the two solutions that can be directly applied by shipping companies. For this reason, Liquefied Natural Gas (LNG) was not examined by ships.

Another reason that caused the writer's interest in studying this particular topic is that it concerns three different specialties, as it includes issues of technical, economic and natural environmental interest. In order to make the reader aware of the pros and cons of each form of compliance, an important part of the work is devoted to their analysis.

In addition, there is an extensive reference to a straightforward comparison of the two compliance strategies in terms of achieving the environmental objective (ie reducing sulfur emissions to almost zero) and their economic attraction.
For this purpose, most of the available published literature has been studied and included.

However, it was considered appropriate to evaluate economically the investment in scrubbers for a real ship (OOCL Hong Kong). For the purpose this used the real data of the ship, adding the factor of reality to the model of work. However, the lack of available data for machine size scrubbers has led to some estimates from earlier published surveys. The instrument for the economic evaluation is the scenario analysis, where the selected ship is used in different profile modes (exposure to ECA zones), influencing the results accordingly. Three well-known investment criteria are used to evaluate the investment: NPV, IRR, and payback period.

\section{CONTENTS OF THE ANNEX VI, MARPOL 73/78}

"International Maritime Organization (IMO)" was established with a mission to protect safety and prevention pollution from ships through "Marpol Annex VI - Regulations for the Prevention of Air Pollution from Ships". In October 2008, the IMO has adopted to set amendments about Annex VI of the MARPOL Convention. The amendments especially concern about sulphur content level limit in marine fuel oil. Besides that, they also provided with a reduction of the sulphur content in marine fuel oil following: from 1 January 2012, the global sulphur cap will be reduced. Firstly, the reduction of sulphur content limit in marine fuel oil is to $3.50 \%$ comparing with current level is $4.50 \%$ and then, the subject is a feasibility review to be implemented no later than 2018. On the other hand, the progress is to $0.50 \%$ from 1 January 2020. In the Sulphur Emission Control Areas (SECAs), the requirements are more strict. Especially, from 1 July 2010, the maximum sulphur limit has been reduced to $1.00 \%$ from $1.50 \%$ while from 1 January 2015 , the limit will be further reduced to $0.10 \%$.

Moreover, following the Regulation 14, Sulphur oxides (SOx) and particulate matter emission controls apply to all fuel oil, and especially from 1 January 2015, all ocean-going vessels travelling within the Emission Control Areas including the English Channel, Baltic Sea, North Sea, North American and US Caribbean Sea areas must use fuel oil with less than $0.10 \%$ sulphur.

Regulation 14: In this regulation, are placed the limits on the sulphur content, of the fuel oil in aims with restricting the SOx and particulate matter (PM) emissions, which are applicable to all ships in service. There is a difference between inside and outside of emission control areas.

On the other hand, two ECA-SOx with Baltic and the North Sea which includes the English Channel are currently in effect and well established from 1 August 2012, a third with the North American ECA-SOx will enter into effect while a 
fourth - the US Caribbean ECA-SOx is intended to enter into effect in January 2014.

\subsection{Abatement Methods}

The options to ensure adherence to regulatory standards include the use of scrubber systems, switching fuel to MGO, and considering dual-fuel engines that can use LNG or rely on shore power for covering energy requirements at berth.

\subsection{Maritime and SECA Compliance}

There are different approaches to satisfy the SECA requirement. The popular choices for ship owners are fuel switching from heavy fuel oil (HFO) to marine gasoline oil (MGO), the installation of LNG engine followed by the use of the LNG fuel and installation of the scrubber into the exhaust of the ship to remove the sulphur from the emission. All these approaches have their pros and cons and different ship owners have built their ECA regulation compliance strategy around one or more of them. Most of their decisions are borne from the contemplation between the capital expenditures and the OPEX of the compliance investments. Mostly, the factors that influence the various compliance methods ship owners make include: (a) fuel prices (b) the area in which the ship usually operates and the regulation it is accountable to (c) the number of days at sea and (d) vessel's lifespan.

\section{MARINE GAS OIL}

MGO is pure distillate oil with a sulfur content lower than $0.1 \%$. It is the only fuel that can be used in conventional marine engines within regulated waters. No major modifications are needed for marine engines to run on MGO. However, fuel must be stored in different tanks when a vessel uses two types. Switching to MGO may affect the engine's performance. MGO has a lower viscosity, and there may be need for additional lubrication to avoid damage to the engine's fuel pumps. Such impacts are not considered in this paper. Historically, MGO has been more expensive than HFO because MGO is more highly processed. Forecasting future fuel prices and price differentials between fuel types is difficult. MGO is expected to increase in price faster than HFO because of the higher demand for low-sulfur fuel. Feasibility studies had predicted a constant increase in fuel prices, which may have made scrubber systems a more attractive option.

\section{LNG}

Natural gas is an option that complies with the low-sulfur regulations. Dual-fuel engines have been designed that can use LNG for ship propulsion. In the past, only LNG carriers would use part of their cargo as fuel, to maintain the cargo tank pressure. The LNG carrier fleet has increased significantly in the past decade, and many ports now offer or plan LNG bunkering facilities. LNG has significant advantages as it results in lower emissions generation, higher fuel efficiency, and lower fuel costs than both MGO and HFO. LNG is expected to play a significant role as marine fuel for container ships in the future, especially for new vessels because fuel economy and compliance with regulations can outweigh higher building costs. The main challenge associated with LNG is that there are few bunkering ports at this stage. Very few ports within ECAs offered LNG bunkering facilities, and for the purposes of this research the use of LNG as an abatement option is not relevant.

\section{EXHAUST GAS CLEANING SYSTEM OPERATION}

The exhaust gas cleaning system (Scrubber) is a device that is installed in the exhaust gas system of the engine and boiler. It is used to treat the exhaust gas with a variety of substances including sea water, chemically treated fresh water or dry substances so as to remove most of the SOx from the exhaust and reduce PM (Particulate Matter) to some extent. After scrubbing, the cleaned exhaust is emitted into the atmosphere. All scrubber technologies create a waste stream containing the substance used for the cleaning process plus the SOx and PM removed from the exhaust gas of the engines and boilers.

SOx (SO2 plus SO3) gases are water soluble. Once dissolved, these gases from strong acids that react with the natural alkalinity of the seawater, or the alkalinity derived from the added substances (normally sodium hydroxide), forming soluble sodium sulfate salt, which is a natural salt in the seas. In addition, the PM in the exhaust will become entrapped in the wash water, adding to the sludge generated by a scrubber. With dry scrubbers calcium hydroxide $(\mathrm{Ca}(\mathrm{OH}) 2)$, or hydrated lime as it is more commonly known, reacts with the SOx and solid calcium sulfate (CaSO4), or gypsum as it is more commonly known, is the product of the reaction. The waste stream and generated sludge have to be processed as per the IMO guidelines before discharge overboard, where allowed or stored and discharged to shore as a waste substance.

\subsection{Wet scrubbers}

The Wet Scrubbers pass the exhaust gas through a liquid medium in order to remove the SOx compounds from the gas by chemically reacting with parts of the wash liquid. The most common liquids are untreated sea water or chemically treated fresh water. Sea water scrubbers are normally open loop-type, where the water is sourced and discharged from outside the system and the water flows only once through the unit. In a closed loop scrubber, the treatment water is cleaned and recycled back to the scrubber in a continuous closed loop. In a closed loop system particulate matter and the water treated to maintain its $\mathrm{pH}$ and then make it suitable for reuse in the scrubber.

Wet SOx scrubbers system is a simple, effective technology that has been used in industrial applications for many years. Wet SOx scrubbers comprise the following components:

- $\quad$ scrubber unit - a vessel or series of closely coupled components which bring water into intimate contact with the exhaust gas from one or more combustion units. The unit is typically mounted high up in the ship in or around the funnel.

- treatment plant for conditioning of washwater before discharge overboard;

- $\quad$ residue handling facility for sludge separated from the wash waster;

- $\quad$ scrubber control and emissions monitoring system.

These components will be interconnected by pipework with various pumps, coolers and tanks, depending on the scrubber system configuration. One piping system and wash water treatment plant may service more than one scrubber. These will also be a monitoring and control system, with instrumentation either dedicated to a single scrubber or shared across an integrated system. 


\subsubsection{Open Loop}

Open-loop scrubbers use seawater as an exhaust leach. The scrubbing process takes place in the scrubber tower, where the exhaust mixture passes through a water separator. This separator removes the particles of water from the gases. The water mixture resulting from the rinsing process ends at the bottom of the scrubber. The rinse water is further processed, either by means of a separator or by centrifugation, to remove the residual process. These sludge residues usually contain heavy metals, PM and etc, and are stored in a special tank on board. Based on the IMO rules, it is prohibited to burn or discard them in the environment, but they must be kept on board and delivered to special waste treatment plants in ports. Rinse water, if cleared from the residues, may be disposed of in the aquatic environment. Based on the water discharges of the IMO, the rinsing water can be dissolved with the water used for cooling to reduce its $\mathrm{pH}$ before it is discharged into the sea (ABS, 2013).

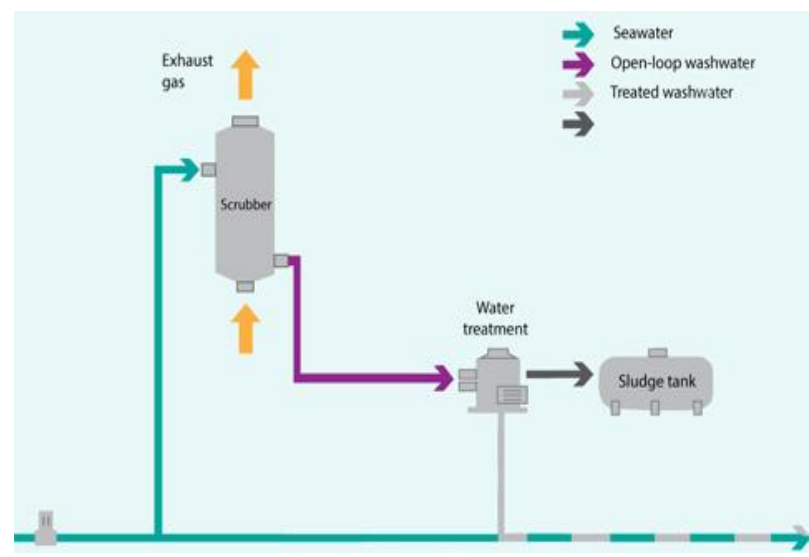

Fig 1: Open-loop scrubber

\subsubsection{Closed Loop}

A closed-loop scrubber is based on the same operating principles as an open-loop scrubber, with two major differences. Firstly, this type of operation is based on the use of chemical additives - usually caustic soda - for exhaust gas spraying. Secondly, the rinsing water, after being treated, is reused in the system with the addition of the necessary chemical adjuvant dosage. This greatly reduces the amount of rinsing water discharged back into the environment (ABS, 2013). The following diagram shows the typical operation of a closed-loop scrubber.

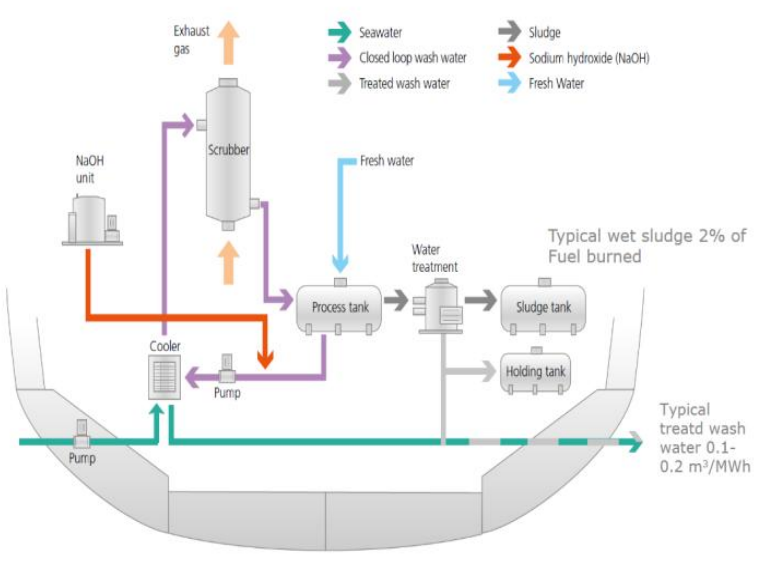

Fig 2: Close-loop scrubber
Particular mention should be made of caustic soda (sodium hydroxide) used as an additive in the leaching process. The reason is that it erodes the aluminum and other materials, so significant changes are required to the materials of the piping and tankers. Particular care must also be exercised in the use of the additive by the crew of the ship. Due to the high $\mathrm{pH}$, it can cause burns and serious damage to the eyes and respiratory system. It is therefore necessary to use protective equipment by the crew.

\subsubsection{Hybrid Scrubbers}

Hybrid scrubbers combine the advantages of open-loop and closed-loop scrubbers. In fact, it is the same system as before, with the necessary conversions that allow switching from one mode of operation to another. Switching from open-loop mode to closed-loop mode is through the different operation of the seawater circulation pump to freshwater (containing chemical additives). The second conversion concerns the nondischarge of flushing water but its concentration in a suitable tank (circulating tank) and its recirculation in the system (ABS, 2013). The diagram that follows is the typical operation of a hybrid scrubber.

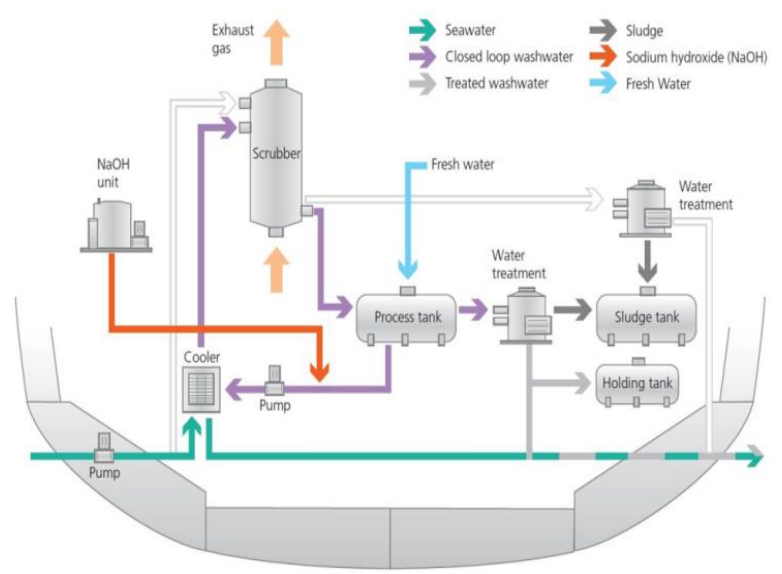

Fig 3: Hybrid scrubber

Although it combines the advantages of open-loop and closedloop scrubbers, the biggest advantage of hybrid scrubbers is the flexibility they offer for operation regardless of the alkalinity of the area's water. So when the ship is in a marine environment with high alkalinity, it operates in open-loop mode without the use of chemical additives. In contrast, in areas with reduced alkalinity it operates in closed-loop mode with the corresponding disadvantages and advantages. But the biggest disadvantage of hybrid scrubbers is the increased cost compared to open-loop and closed-loop scrubbers (Lloyds Register, 2015).

\section{CASE STUDY OF SCRUBBER INSTALLATION / INVESTMENT EVALUATION}

In this section the hypotheses of the case study scenario and all the parameters taking place will be defined.

The presented project is the economic analysis of the installation of a "scrubber" system in OOCL Hong Kong container ship. This after-treatment system reduces the emissions of SOx, in order to meet the latest IMO's legislation for ECA zones. Some data concerning the ship's fuel consumption and the installation cost have been founded by the project made by "Greenship of the future" industry and "The Danish Maritime Fund". The purpose of the study is the calculation of NPV and Payback Period of this investment. 
The installation cost of the system is shown below.

The scrubber will have to endure $72.677,5 \mathrm{~kW}$.

Based on Wärtsilä data a scrubber of this size will cost:

$€ 1,6 \mathrm{M}+72677,5 * € 70=6,7 \mathrm{M} € 6,7 \mathrm{M} * 1,622=10,9 \mathrm{M}$

The cost of the investment scrubber, according to the dollar exchange rate $(1,156 /$ June 18$)$ is $12.6 \mathrm{M} \$$.

Table 1. The average daily fuel consumption of the main engine and the auxiliary engines

\begin{tabular}{|lc|}
\hline \multicolumn{2}{|l|}{ ME consumption at sea } \\
\hline HFO $\quad 236,5 \mathrm{t} /$ day \\
\hline MGO 219 t/day \\
\hline AE consumption at sea \\
\hline HFO & 49,4 t/day \\
\hline MGO & 45,7 t/day \\
\hline AE consumption, harbour \\
\hline HFO & 108,9 t/day \\
\hline MGO & $100,8 \mathrm{t} /$ day \\
\hline
\end{tabular}

We haven't included the off-hire cost for the installation time needed, the training cost of the crew on the system as well as the cost of $\mathrm{NaOH}$ needed in order to work.

In addition to the installation cost, we quote the consumption table above. The ship can operate with both MGO (Marine Gas Oil) low sulphur fuel and HFO (Heavy Fuel Oil).

In the presented scenario, the results attributed, will be given for different percentages of ECA activity and different gap in the prices of HFO and MGO low sulphur. However, in all the scenarios investigated we will keep the hypothesis of the chart pie, shown below, constant. So from 365 days of a year we assume that our ship will travel at sea for 274 days and will remain idle in harbor for 91 days.

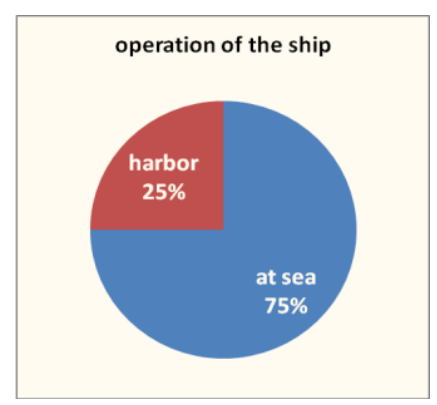

Fig 4: Operation of the ship

The main engines operate at $75 \%$ of the maximum continuous rating (MCR) and the auxiliary engines at $25 \%$ of the MCR, with the ultimate goal of reducing fuel consumption and therefore cost. As long as the ship is in port, auxiliary engines operate at $95 \%$ of the MCR.

Making all the needed calculations we can presume that the profit function has two variables, the percentage of traveling and staying in an ECA zone and the difference in the prices of the HFO and MGO low sulphur fuels. The profit function is given below:

$$
\begin{gathered}
P F=x\left(c_{M G O} *(\text { HFOprice }+\boldsymbol{g})-\boldsymbol{c}_{\text {HFO }} *\right. \\
\text { HFOprice })(1)
\end{gathered}
$$

$C_{H F O}=88246,5$

$C_{M G O}=\mathbf{8 1 7 0 0 , 6}$

$x$ : Percentage of travelling and being in ECA Zones

$g$ : the gap between the price of HFO and MGO low sulphur.

\subsection{Fuel price}

\section{Bunker price difference $\$ / \mathrm{mt}^{*}$}

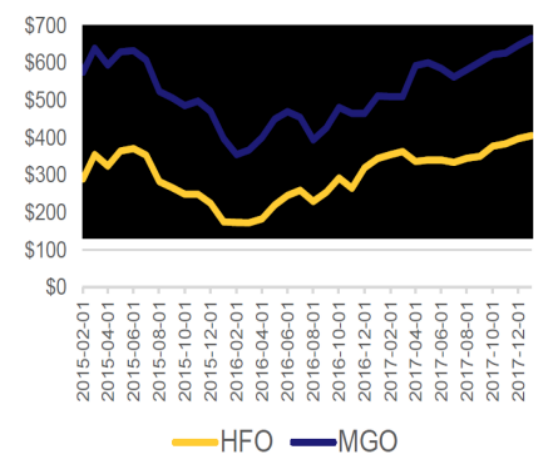

\begin{tabular}{|c|c|c|}
\hline & IFO380 & MGO \\
\hline & $\$ / m t \quad+/-$ & $\$ / m t$ \\
\hline Singapore & $399.00>0.00$ & $623.50 \triangle 2.50$ \\
\hline Rotterdam & $374.50>0.00$ & $611.50 \backsim 0.50$ \\
\hline Houston & $371.50 \backsim 2.00$ & $639.50 \triangle 7.00$ \\
\hline Fujairah & $396.00 \times 2.00$ & $680.00 \backsim 7.50$ \\
\hline
\end{tabular}

*Based on global average per $m t$ at Bunkerworld.com as per 1-02-2018

Fig 5: Fuel price

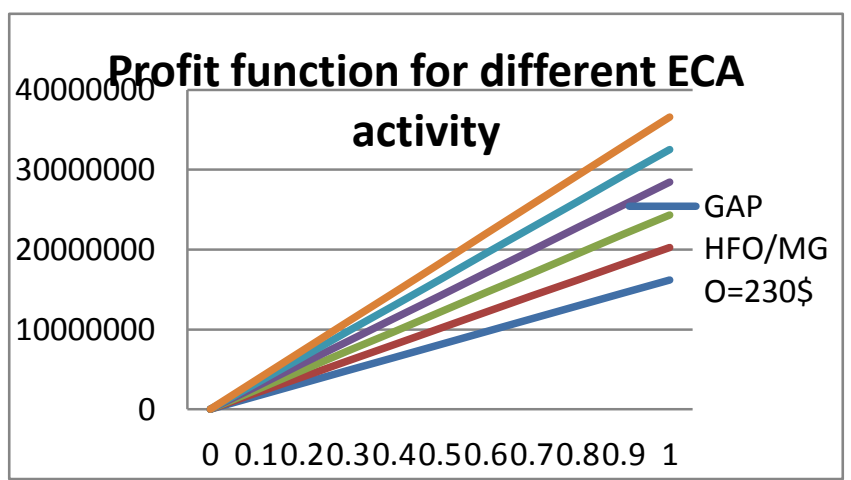

Fig 6: Profit function for different ECA activity

The outcomes from the figure above is the logical relationship between the gap of the HFO and the MGO Low Sulphur prices and the revenue function. As this price gap grows, the income of the shipowner is going to grow too. The values of the price gap used to calculate and produce the figure above are 230 to 480USD, with a step of 50USD

The same phenomenon happens as long as we increase the activity of the ship into an ECA Zone. It has to be mentioned that the common percentage of the activity of ships is about $10 \%-15 \%$. 


\subsection{NPV}

For pages other than the first page, start at the top of the page, and continue in double-column format. The two columns on the last page should be as close to equal length as possible. For the NPV calculation we will enter 3 values for the activity in an ECA zone, ie $10 \%, 20 \%$ and $30 \%$.

This ECA rate is used to suppose that new ECA bands such as the Mediterranean Sea, the Indonesian Sea, etc. are added. Thus, the activity of ships in ECA tends to increase beyond 2020 .

So the NPV will be given from the following function. We assume that the installation cost does not have the shape of a loan and is paid wholly in the first year.

$N P V=$

$-12600000+\sum_{i=0}^{n} \frac{x\left(c_{M G O} *(H F O p r i c e+g)-c_{H F O} * H F O p r i c e\right)}{(1+r)^{i}}$

r: inflation rate $3 \%$

i: years

$\mathrm{n}$ : in this study up to 15 years

\subsection{Scenarios}

Starting from the baseline scenario of the survey, the ship spends about $10 \%$ of its time in an ECA zone and the current difference of the two types of fuel is $\$ 230$. The table shows the results obtained from the model used for the purposes of the study.

Table 2. Results Scenario 1

\begin{tabular}{|l|l|}
\hline pv & $6.714 .771,85 \$$ \\
\hline NPV & $19.314 .771,85 \$$ \\
\hline IRR & $9,59 \%$ \\
\hline pay back & $8,10 \mathrm{y}$ \\
\hline
\end{tabular}

As shown above, investing in a scrubber "produces" a positive NPV, so it is cost-effective. Correspondingly, IRR (9.59\%) is higher than the discount rate $(3 \%)$, confirming the NPV results. However, the real problem, it seems, is the reimbursement period. The 8.1 years that are required to cover the initial cost of the investment are many, especially if you take into account that the investment period is 15 years. Recovery time results from the high cost of buying and installing the scrubber on the one hand, and on the other hand the resulting savings are small enough to justify such a costly investment.

In the second scenario, as in the first scenario, the ship spends about $10 \%$ of its time in an ECA zone but the current difference of the two types of fuel is increasing. It was calculated with a step of $\$ 100$, so from \$230 to \$330 and \$ 430.

Table 3,4. Results Scenario 2

\begin{tabular}{|l|r|}
\hline MGO-HFO & $330 \$$ \\
\hline pv & $16.468 .136,44 \$$ \\
\hline NPV & $29.068 .136,44 \$$ \\
\hline IRR & $17,63 \%$ \\
\hline pay back & 5,11 \\
\hline
\end{tabular}

\begin{tabular}{|l|r|}
\hline MGO-HFO & $430 \$$ \\
\hline pv & $26.221 .501,03 € \$$ \\
\hline NPV & $38.821 .501,03 \$$ \\
\hline IRR & $24,89 \%$ \\
\hline pay back & 4,03 \\
\hline
\end{tabular}

As can be seen from the Tables, investments in scrubber "produce" a positive NPV, so it is economically advantageous.

As it turns out as the price difference of the two fuels grows while the ship remains in ECA zone, the investment is so advantageous and the time for recuperation is reduced by 5.11 years and 4 years respectively. This scenario is very likely to happen because of the stricter regulations that will apply from 2020. Demand for low-sulfur fuels will be high, thus increasing their price and hence the difference with HFOs.

In the third scenario, it is considered that new ECA zones such as the Mediterranean Sea, the Indonesian Sea, etc. will be added. Thus, ship's activity at ECA will increase. Under this scenario the ship spends about $30 \%$ of its time in ECA zones. The difference of the two fuels will remain constant at $\$ 2$ 230.Increasing time within ECA produces very different results, as shown in the Table

Table 5. Results Scenario 3

\begin{tabular}{|l|l|}
\hline pv & $45.344 .315,54 \$$ \\
\hline NPV & $57.944 .315,54 \$$ \\
\hline IRR & $38,22 \%$ \\
\hline pay back & 2,24 \\
\hline
\end{tabular}

And in this case the investment in a scrubber produces a positive NPV, so it is economically advantageous. Impression is caused by the very high IRR $(38.22 \%)$, well above the discount rate. The very short payback time just 2.24 years makes the investment really attractive. The above resulting from significant savings in fuel costs due to increased time in an ECA zone.

The last scenario examines the case of an increase in both factors, ie an increase in the ECA zone and an increase in the price difference of the two fuels. The increase of the 2 factors gives the expected results compared to the previous 2 scenarios, as shown below.

Table 6. Results Scenario 4

\begin{tabular}{|l|l|}
\hline pv & $103.864 .503,10 \$$ \\
\hline NPV & $116.464 .503,10 \$$ \\
\hline IRR & $77,41 \%$ \\
\hline pay back & 1,17 \\
\hline
\end{tabular}


Therefore, a very high NPV and an almost unrealistic IRR of $77.4 \%$ are produced, clearly indicating that the investment is economically viable and needs to be undertaken.

This view is reinforced by the very short pay back period of about one year which is enough to over-cover the initial cost of investing in a scrubber.

\section{CONCLUSION}

The research and analysis that preceded, show the strictest environmental regulations that have already begun to emerge in the past few years and have to do with reducing SOx emissions to the lowest possible levels. The shipping business can only choose how to comply with these regulations in the near future.

This research analyzes the advantages and disadvantages of each model of compliance through their environmental and financial assessment. Each of the two models of compliance has its own advantages but also drawbacks. It is therefore up

\section{ACKNOWLEDGMENTS}

All authors would like to thank the University of West Attica and specifically the Post Graduate Program of Studies (MSc) "New Technologies in Shipping and Transport", for the financial support provided to them to undertake this research project.

\section{REFERENCES}

[1] Fernandez Soto,J.L., Garay Seijo, R., Fraguela Formoso, J.A., Gregorio Iglesias, G.,\& Carral Couce, L. (2010). Alternative Sources of Energy in Shipping. THEJOURNAL OF NAVIGATION, 63, 435-448

[2] Vogler F.\& Sattler G. (2016). Compendium of Hydrogen Energy; Volume 4:

[3] Hydrogen Use, Safety and the Hydrogen Economy, Woodhead Publishing, 35-66

[4] Dalaklis D, Olcher A., Balini F.\& Dewitz L. J. (2016). Protecting the Arctic

[5] Environment: Challenges and Opportunities for Liquefied Natural Gas. Retrieved from https://www.researchgate.net/publication/309264253_Pr otecting_the_Arctic

[6]_Environment_Challenges_and_Opportunities_for_Liqu efied_Natural_Gas

[7] Schinas O. \& Butler M.. (2016). Feasibility and commercial consideration of LNGfueled ships, Ocean Engineering, 112, 84-96

[8] Edwards, D.T. \& Rymarz, E. (1990), International Regulations for the Prevention and Control of Pollution by Debris From Ships, In R. S. Shomura and M. L. Godfrey (editors), Proceedings of the Second International Conference on Marine Debris, 2-7 April 1989, Honolulu, Hawaii. U.S. Dep. Comer., NOM Tech. Memo. NMFS, NOM-TM-NMFS-SWFSC-154, pp 956 988.

[9] I.P.I.E.C.A., (2007), Maritime air emissions and MARPOL Annex VI, Strategies and consequences, International Petroleum Industry Environmental Conservation Association (I.P.I.E.C.A.),

[10] Icopal-Noxite. (n.d.). Nitrogen Oxide (NOx) Pollution. Icopal-Noxite. Retrieved from http://www.icopalnoxite.co.uk/nox-problem/nox-pollution.aspx to each shipping company to analyze its economic and operational parameters and to decide accordingly.

Concerning the conclusions drawn from this work, the key role played by the scrubbers' investment in both the exposure time in ECA zones and the price difference between HFO and distillates was confirmed. With regard to exposure time, the four different scenarios examined were given the opportunity to evaluate the investment under different circumstances. The investment criteria used (NPV, IRR, and payback period) have shown that investing in scrubbers is economically advantageous in all four cases and should, therefore, be undertaken. Indeed, as the ECA exposure time increased from $10 \%$ to $30 \%$ respectively for each scenario, the higher NPV and IRR, and the time to recover the initial investment, was reduced. This negative relationship between the exposure time and the recovery period, as well as the positive relationship between the NPV and the exposure time, have been evident from the published literature and are also confirmed by this research.

[11] USEPA. (n.d.). Sulphur Dioxide Basics. Unite State Environmental Protection

[12] Agency. Retrieved from https://www.epa.gov/so2pollution/sulphur-dioxidebasics\# Effects

[13] Motorship. (2015). Meeting the EEDI challenge. Motorship. Retrieved from

[14] http://www.motorship.com/news101/engines-andpropulsion/eedi-andpropulsion-power

[15] ABS (2013), Exhaust Gas Scrubber Systems: Status and Guidance, Available at:http://ww2.eagle.org/content/dam/eagle/publications/2 013/Scrubber_Advisory.pdf

[16] EU (2012), Directive 2012/33/EU of the European Parliament and of the Council of 21 November 2012, Available at: http://eur-lex.europa.eu/legal

[17] Reynolds K. (2011), Exhaust Gas Cleaning Systems Selection Guide, Prepared for Ship Operations Cooperative Program (SOCP), Available at: http://www.procal.com/docs/Exhaust_Gas_Cleaning_Sys tems_Guide.pdf

[18] Allwright Gavin. (2017). Commercial Wind Propulsion Solutions: Putting the "Sail"Back into Sailing, MARINER217 Conference

[19] Jose J.D., Carlos A., Carlos F.G., \& Luis C. (2016). Analysing the possibilities of using fuel cells in ships. International Journal of Hydrogen Energy. 2853-2866

[20] DeMates Lauren. (2016). What are the differences between Biofuels, Bioethanol,Biodiesel and Biogas? The Sustainability Co-Op. Retrieved from

[21] https://thesustainabilitycooperative.net/2013/12/26/thedifference-between 56

[22] biofuel-bioethanol-biodiesel-and-biogas/

[23] Kronemeijer Dirk. (2016). Bring on the Biofuels. Shipping \& Marine. Retrieved from

[24] http://www.shipping-and-marine.com/2016/05/11/bringon-the-biofuels/

[25] Xu Jingjing, Testa David \& Mukherjee roshanto Kinter. (2015). The Use of LNG as a Marine Fuel: The International Regulatory Framework, Ocean 
Deveopment \& International Law, 43:3, 225-240

[26] EIA (U.S. Energy Information Administration). (2013). Technically Recoverable Shale Oil and Shale Gas Resources: An Assessment of 137 Shale Formations in 41 countries Outside of United States. 2

[27] 'EU launches clean fuel strategy'. (2013). European Commission. Retrieved from http://europa.eu/rapid/press-release_IP-13-40_en.htm

[28] WPCI. (2016). World Ports Climate Initiative. Retrieved from

[29] http://www.lngbunkering.org/lng/map/node

[30] DNV (2014), Sulfur Limits 2015 - Guidelines to ensure compliance, Available at:

https://www.dnvgl.com/maritime/low-sulphuroperation.html

[31] CONCAWE (2009), Impact of marine fuels quality legislation on EU refineries at the 2020 horizon , Available at:

https://www.concawe.eu/uploads/Modules/Publications/r pt_09-3-2009-01906-01-e-2.pdf

[32] Kristensen, H.O. (2012), Energy Demand and Exhaust Gas Emissions of Marine Engines, Technical University of Denmark, Project no. 2010-56,

[33] Emissionsbeslutningsstøttesystem, Work Package 2, Report No. 05, September.

[34] EGCSA Handbook 2012 A practical guide to exhaust gas cleaning systems for the maritime industry

[35] Dan Rutherford, Azzara Alyson, Haifeng Wang, 2014

[36] Feasibility of IMO Annex VI Tier III implementation using Selective Catalytic Reduction,

[37] Køcks, M. et al., 2012. Shipboard characterization of a wet scrubber

[38] system:Influence on particle number concentration, particle size distribution
[39] and chemical composition.

[40] Hassellöv, I.-M., Turner, D. R., Lauer, A. \& Corbett, J. J., (2013), Shipping

[41] contributes to ocean acidification, Geophysical Research Letters, Volume 40, pp. 2731-2736, Available online at: http://onlinelibrary.wiley.com/doi/10.1002/grl.50521/pdf

[42] Buhaug, Halvard and Jan Ketil Rød. 2006. Local determinants of African civil wars, 1970-2001. Political Geography 25(3): 315-335.

[43] UBA, 2014. Auswirkungen von Abgasnachbehandlungsanlagen (Scrubbern) aufdie Umweltsituation in Häfen und Küstengewässern, TEXTE 83/2014,, Bremen: Umweltbundesamt (UBA).

[44] Ma, H., Steernberg, K., Riera-Palou, X. \& Tait, N., 2012. Well-to-wake energy

[45] and greenhouse gas analysis of SOX abatement options for the marine industry.

[46] Transportation Research, 17(Part D), pp. 301-308.

[47] "ABS Record: OOCL Hong Kong". Retrieved 2017-0607.

[48] "OOCL reaches milestone with the christening of the OOCL Hong Kong". OOCL. 12 May 2017. Retrieved 16 May 2017.

[49] Klimt-Møllenbach, C., Schack, C., Eefsen, T., \& Kat, J. D. (2012). ECA Retrofit Technology. Green Ship of theFuture. Retrieved from

[50] http://www.greenship.org/fpublic/greenship/dokumenter/ Downloads\%20-

[51] \%20maga/ECA\%20study/GSF\%20ECA\%20Technical\% 20report.pdf

[52] Wahlström, J., Karvosenoja, N., \& Porvari, P. (2006). Ship emissions and technical emission reduction potential in the Northern Baltic Sea. Helsinki: Finnish Environment Institute. 